\title{
Gender differences in the inhibitory effects of a reduction in ambient temperature and a reduction in food quantity on reproduction in the Southern African rodent, Rhabdomys pumilio
}

\author{
C. Jackson and R. T. F. Bernard* \\ Department of Zoology and Entomology, Rhodes University, Grahamstown 6139, \\ South Africa
}

The effects of a reduction in ambient temperature (from $26^{\circ} \mathrm{C}$ to $15^{\circ} \mathrm{C}$ ) and a $10 \%$ reduction in daily food consumption on reproductively active male and female four-striped field mice (Rhabdomys pumilio) were investigated. In male $R$. pumilio, both reduced ambient temperature and a reduction in food quantity had an inhibitory effect on spermatogenesis and on size of the reproductive organs, and this was greatest when the two factors were combined and the effect of fat was removed. Female $\boldsymbol{R}$. pumilio responded differently and reproduction was inhibited by a reduction in food quantity, irrespective of ambient temperature. The masses of the ovaries and uterus, the numbers of developing follicles and corpora lutea, and the development of the uterine wall were all reduced by food deprivation at $26^{\circ} \mathrm{C}$ to levels similar to those that resulted from a reduction in ambient temperature to $15^{\circ} \mathrm{C}$ with a reduction in food quantity. It is concluded that reproduction in $R$. pumilio from the Eastern Cape Province of South Africa is opportunistic, that reproduction will be inhibited by an energetic challenge and that there is sexual dimorphism in the response to ambient temperature and food supply.

\section{Introduction}

Most rodents are small and suffer the thermoregulatory problems associated with a high surface area to volume ratio. In addition, their small size restricts their ability to store large amounts of fat and limits their ability to migrate; hence, reproduction is inhibited readily by factors such as a reduction in ambient temperature and reduction in the quantity or quality of food (Bronson, 1989). Although their small size leaves them susceptible to reproductive inhibition, most rodents have short lifespans and, thus, evolutionary forces will favour continuous reproduction unless reproductive inhibition results in an extended lifespan (Bronson, 1989). Thus, reproduction in small mammals is a trade-off between evolutionary pressure for continuous reproduction in a short lifespan and susceptibility to environmental inhibition of reproduction. Therefore, the timing of rodent reproduction is usually shaped by complex interactions between a range of environmental, physiological and social factors (Harvey and Zammuto, 1985; Partridge and Harvey, 1985; Bronson, 1989; Read and Harvey, 1989; Promislow and Harvey, 1990; Bronson and Heideman, 1994) and it is for this reason that small mammals show such a diverse array of patterns of reproduction.

*Correspondence

Email: R.Bernard@ru.ac.za
Most studies of the control of rodent reproduction have been undertaken at temperate or subtropical latitudes and have used seasonally breeding species as models (for example, Rattus fuscipes: Irby et al., 1984; Mus musculus: Hamilton and Bronson, 1985; Peromyscus maniculatus: Nelson et al., 1992; Saccostomus campestris: Bernard and Hall, 1995). At temperate latitudes the climate is strongly seasonal and predictable, and most species and populations of small mammals use photoperiodic cues to trigger and inhibit reproductive activity (Clarke, 1985; Bronson, 1989; Nelson et al., 1992; Bronson and Heideman, 1994). However, at lower latitudes the seasons are often far less predictable (Jackson and Bernard, 1999) and the extent of the seasonal change in daylength is less than at temperate latitudes and, for these reasons, it has been predicted that the use of photoperiod as a cue for controlling reproduction will decrease with decreasing latitude (Bronson, 1989; Bronson and Heideman, 1994). Indeed, there is increasing support for this prediction and photoperiod has little effect on reproduction in Pteropus scapulatus (O'Brien et al., 1993), Saccostomus campestris (Bernard and Hall, 1995), Rhabdomys pumilio (Jackson and Bernard, 1999) and Cavia aperea (Trillmich, 2000) from subtropical and tropical latitudes. At lower latitudes, more variable factors such as rainfall, ambient temperature, food availability and food quality, or a combination of these factors, may be used by rodents to control their reproduction and a more flexible, opportunistic reproductive activity will result.

Rhabdomys pumilio, the four-striped field mouse, is a 
small, diurnal, omnivorous rodent (De Graaf, 1981) that occurs in subtropical areas of Africa. Its reproduction is reported to be seasonal with inhibition in winter (Hanney, 1965; Brooks, 1974; Perrin, 1980; Henschel et al., 1982; David and Jarvis, 1985) although there are a few records of reproduction in winter (Botswana: Smithers, 1971; Western Cape of South Africa: David and Jarvis, 1985). Spermatogenesis is not inhibited by short daylength alone (Jackson and Bernard, 1999) and in this study the hypothesis that reproduction in the four-striped field mouse is opportunistic (Bronson, 1989) and that reproductive activity of males and females will be inhibited by a reduction in food quantity or a reduced ambient temperature or both was investigated.

\section{Materials and Methods}

\section{Animals and pre-acclimation}

Experiments were carried out in late summer (MarchApril) of two consecutive years when reproductively active males (1998) and females (1999) were subjected to either reduced ambient temperature, reduced food availability or both reduced ambient temperature and reduced food availability. Experimental procedures were approved by the Rhodes University Ethical Standards Committee. The design of the two experiments was similar and a single description is given.

Adult (mice weighing $>35$ g) Rhabdomys pumilio (40 males and 38 females) were collected from Thomas Baines Nature Reserve in the Eastern Cape Province of South Africa $\left(33^{\circ} 18^{\prime} \mathrm{S} 26^{\circ} 32^{\prime} \mathrm{E}\right)$ during February 1998 and January to February 1999, and from Brentwood Farm $\left(33^{\circ} 29^{\prime} \mathrm{S}\right.$ $26^{\circ} 09^{\prime} \mathrm{E}$ ) during March 1999 . On the day of capture, the mice were brought into the laboratory where they were housed singly in similar sized cages $(41 \mathrm{~cm} \times 26 \mathrm{~cm} \times 15 \mathrm{~cm})$ in controlled environment rooms. The mice were provided with shredded paper and a toilet roll for bedding, and the females were also given a square of blanket for additional bedding. Water and food (rabbit pellets: $16 \%$ protein, $17 \%$ fibre, energy content of $17.05 \mathrm{~kJ} \mathrm{~g}^{-1}$; Epol, Johannesburg) were provided ad libitum. Although the four-striped field mouse is described as an unspecialized omnivore (De Graaf, 1981) we have used rabbit pellets in our previous experiments (Jackson and Bernard, 1999) and the species will reproduce on this diet (personal observation). Females that were pregnant at the time of capture were allowed to give birth and remained with their young until weaning occurred (day 14), at which time the young were removed from the cages. During this pre-acclimation period, the mice were exposed to a photoperiod of $18 \mathrm{~h}$ light: $6 \mathrm{~h}$ dark, temperature $26^{\circ} \mathrm{C}$ and humidity of $40 \%$ (summer conditions).

At the end of the experiment with male $R$. pumilio in 1998 it was noted that some of the mice were infested with tapeworms. As it is likely that this type of parasitic infestation will aggravate the effect of food deprivation, the females (1999 experiment) were treated with a Lintex
(Bayer: active ingredient Niclosamide) solution, where $5 \mathrm{ml}$ (concentration $=0.0065 \mathrm{~g} \mathrm{ml}^{-1}$ ) of the solution was forcefed to each mouse in the week preceding the start of acclimation.

\section{Acclimation}

In both experiments, mice were allocated to one of two groups so that there was no significant difference between the mean body weight, hind foot length and the reproductive status of the mice in each group. One of the groups was placed into a controlled environment room at $26^{\circ} \mathrm{C}$ and the other was placed into a controlled environment room at $15^{\circ} \mathrm{C}$. The photoperiod for both controlled environment rooms was $12 \mathrm{~h}$ light:12 h dark and the humidity was about $40 \%$. Mice were fed pre-weighed food (rabbit pellets) ad libitum and water was available continuously. The mice were weighed and the reproductive status of the males (scrotal, moving scrotal (where the testes readily slip between a scrotal and non-scrotal position) or non-scrotal testes) was noted every 2 days. Assessment of the reproductive status of the females (perforate or non-perforate vagina) required prolonged handling of the mice and their reproductive status was recorded at the start of the acclimation period only. Cages were cleaned once a week and the uneaten food that had accumulated during that week was discarded. At the end of the last week of acclimation, which lasted for 2 weeks in the male experiment and for 3 weeks in the female experiment, the leftover, uneaten food for that week was collected and used to calculate the weekly food intake for each mouse.

\section{Experimental design}

At the start of the experimental period, the mice in each controlled environment room were divided into two groups (Table 1) so that there was no significant difference between the mean body weight, hind foot length and the reproductive status of the mice. One group per controlled environment room served as the control group and was maintained on the pre-weighed, ad libitum diet of rabbit pellets, and the second group per controlled environment room was provided with a food-restricted diet of rabbit pellets, where each mouse was given $90 \%$ of its food intake during the final week of acclimation. In a preliminary experiment with this species, a reduction in food of $>10 \%$ resulted in rapid loss of body weight and death (personal observation). All mice were fed daily and were weighed every Monday, Wednesday and Friday. The reproductive status of the males was noted at each weighing, whereas that of the females was noted at the start of the experimental period, during week 6 of the experiment and again at dissection. Animals that lost $>30 \%$ of their mean body weight, as calculated during acclimation, were provided with additional food until mass loss was $<30 \%$.

The experimental period for the males was designed originally to be 8 weeks; however, after 4 weeks it was clear that the mice had responded to the experimental conditions 
Table 1. Sample sizes of Rhabdomys pumilio treatment groups at the start and at the end (in brackets) of the experimental period for the four experimental groups

\begin{tabular}{llrrr}
\hline & \multicolumn{4}{c}{ Experimental group } \\
\cline { 2 - 5 } & $15 \mathrm{FR}$ & $15 \mathrm{AL}$ & 26FR & $26 \mathrm{AL}$ \\
\hline Males & $10(7)$ & $10(9)$ & $10(7)$ & $10(7)$ \\
Females & $11(10)$ & $9(8)$ & $9(9)$ & $9(8)$ \\
\hline
\end{tabular}

15FR: $15^{\circ} \mathrm{C}$, food-restricted diet; $15 \mathrm{AL}: 15^{\circ} \mathrm{C}$, ad libitum diet; $26 \mathrm{FR}: 26^{\circ} \mathrm{C}$, food-restricted diet; $26 \mathrm{AL}: 26^{\circ} \mathrm{C}$, ad libitum diet.

and the experiment was terminated. The experimental period for the females lasted 8 weeks. At the end of the last week of the experimental period, all remaining uneaten food was collected from the cages and used to calculate the weekly food intake for each animal during the experiment. As the cages were cleaned and leftover food was discarded at the end of each week, the uneaten food that was collected at the end of the experiment was from the final week of the experiment only. The mice exposed to the foodrestricted diet ate all the food provided, and leftover food was collected from the cages of the mice on the ad libitum diets only. At the end of the experiment the mice were killed by s.c. injection of $0.2 \mathrm{ml}$ Euthanase (sodium pentobarbitone; Centaur Labs, Bryanston) and weighed. The testes, epididymides and the accessory gland complex (composed of the seminal vesicles, coagulatory glands and the prostate gland) were removed from each male, weighed and fixed in Bouin's solution for light microscopy. The uterine horns, oviducts and ovaries were removed from the females and fixed in Bouin's solution. After fixation, fat was removed from these organs and they were weighed as a whole. For both sexes, the amount of fat around the reproductive organs, the kidneys and under the skin was assessed and given a subjective score from 0 to 3 (= the fat index). A number of animals died at various stages during the experiments and the final sample size is shown (Table 1). Although the animals that died during the experiment were dissected, the data for these mice were not included in any of the analyses.

\section{Histological analysis}

The reproductive organs were prepared for light microscopy using standard techniques. For each male, 100 randomly selected sections through seminiferous tubules from at least two sections through each testis were examined and classified as spermatogenically inactive (tubule lined by spermatogonia and Sertoli cells only), early spermatogenesis (seminiferous epithelium of spermatogonia and spermatocytes) or late spermatogenesis (spermiogenesis occurring with spermatozoa in the lumen of the tubule). An individual was placed into a specific category if $>70 \%$ of the tubules were in a particular condition (Bernard and Hall, 1995). Twenty sections through the cauda epidi- dymides were examined and each animal was given a qualitative score depending on the amount of spermatozoa present in the sections (0: no spermatozoa present; 3: cauda epididymides more than three-quarters full of spermatozoa). The activity of the seminal vesicles was determined in a similar way; the score was based on the amount of stored secretory material in 20 sections through the gland. For each experimental group, these scores were expressed as a percentage of the maximum possible score. All scoring was done separately by the two authors and where there were discrepancies in the scores, the slides were re-examined and a consensus was reached.

Four sets of four serial sections were cut through the centre of each ovary per animal. These were examined and the numbers of secondary follicles, Graafian follicles and corpora lutea were recorded. The greatest diameter of each corpus luteum was measured using an optical micrometer and the extent of the vascularization was noted and given a subjective score (0: no vascularization; 3 : highly vascularized). Two serial sections through one uterine horn from each female were examined and the total thickness of the uterine wall, the thickness of the endometrium and the thickness of the myometrium were measured at two places on opposite sides of the uterine horn. The total number of uterine glands was counted in the same sections.

\section{Statistical analyses}

Throughout this paper the four treatment groups are identified by a code that uses the temperature of the controlled environment room $\left(26^{\circ} \mathrm{C}\right.$ or $\left.15^{\circ} \mathrm{C}\right)$ followed by the diet (ad libitum or food restriction). For example, 26FR is the group from the room at $26^{\circ} \mathrm{C}$ that were kept on the food restriction diet. Mean values from the four groups were compared using multi-factorial analyses of variance (MANOVA), multi-factorial analyses of covariance (MANCOVA), Student's $t$ tests and the non-parametric equivalents where applicable (Zar, 1996). Body weight at the start and end of the experiment was compared using a repeated measure $t$ test. Differences were considered significant at $P<0.05$ and data are represented as mean \pm 1 SEM throughout.

\section{Results}

\section{Experiment 1 (males)}

At the start of the experiment the mice, which had been caught during the breeding season, were all of adult size and had either scrotal or moving scrotal testes (Table 2). At the end of the experiment six $(86 \%)$ of the $26 \mathrm{AL}$ mice still had scrotal testes, whereas only two (29\%) of the 26 FR mice had scrotal testes and three $(43 \%)$ had non-scrotal testes. Only two (22\%) of the 15AL mice had scrotal testes and all of the 15FR mice had non-scrotal testes (Table 2).

A key requirement of this study was that the mice on the food-restricted diet would lose weight and it was expected that exposure to both food restriction and reduced ambient 
Table 2. The effect of a reduction in ambient temperature and food availability on body weight and position of the testes of Rhabdomys pumilio

\begin{tabular}{|c|c|c|c|c|c|c|c|c|c|}
\hline \multirow{2}{*}{$\begin{array}{l}\text { Experimental } \\
\text { group }\end{array}$} & \multicolumn{2}{|c|}{ Mean body weight \pm 1 SEM $(g)$} & \multirow{2}{*}{$\begin{array}{l}\% \text { Change in } \\
\text { body weight }\end{array}$} & \multicolumn{2}{|c|}{ Scrotal (\%) } & \multicolumn{2}{|c|}{ Moving scrotal (\%) } & \multicolumn{2}{|c|}{ Non-scrotal (\%) } \\
\hline & Start & End & & Start & End & Start & End & Start & End \\
\hline $26 \mathrm{AL}$ & $45.2 \pm 2.1$ & $49.2 \pm 2.2$ & +8.9 & 90 & 86 & 10 & 14 & 0 & 0 \\
\hline 26FR & $42.3 \pm 1.6$ & $36.7 \pm 2.1$ & -13.2 & 80 & 29 & 20 & 29 & 0 & 42 \\
\hline $15 \mathrm{AL}$ & $41.1 \pm 1.8$ & $43.9 \pm 1.8$ & +6.8 & 70 & 22 & 30 & 56 & 0 & 22 \\
\hline 15FR & $39.9 \pm 2.2$ & $30.4 \pm 1.9$ & -23.8 & 80 & 0 & 20 & 0 & 0 & 100 \\
\hline
\end{tabular}

26AL: $26^{\circ} \mathrm{C}$, ad libitum diet; $26 \mathrm{FR}: 26^{\circ} \mathrm{C}$, food-restricted diet; $15 \mathrm{AL}: 15^{\circ} \mathrm{C}$, ad libitum diet; $15 \mathrm{FR}: 15^{\circ} \mathrm{C}$, food-restricted diet.

The occurrence of mice with scrotal, moving scrotal and non-scrotal testes is given as a percentage. Note that the sample size at the end of the experiment differed from that at the start.

temperature would result in greater weight loss than exposure to food restriction only. Indeed, within the experimental groups, there was a significant decrease in body weight from the start to the end of the experiment for the mice on the food-restricted diets (repeated measures $t$ test; $P<0.005$ ), whereas no significant change was observed in the mice on the ad libitum diet (Table 2). The mice on the ad libitum diets gained similar percentages of their original weight (Table 2), whereas those in the 15FR group lost a much greater percentage of their original weight $(23.8 \%)$ than did the mice in the 26FR group (13.2\%; Table 2). A comparison of the mean body weights at dissection of the mice from the four groups (Fig. 1a) showed that although reduced temperature and food restriction each had a significant negative effect (MANOVA; $P<0.01$ ), there was no significant interaction between the two factors.

Analysis of food consumption in the final week of the experiment showed that the mice on the ad libitum diet at $15^{\circ} \mathrm{C}$ ate significantly more than did those on the ad libitum diet at $26^{\circ} \mathrm{C}$ (Fig. $1 \mathrm{a}$; ANOVA; $P<0.05$ ).

Experimental reduction in ambient temperature and food availability had a negative effect on the size of the reproductive organs of the mice, which were smallest in the 15FR group and largest in the 26AL group (Fig. 1b-d). Statistical analysis of these data indicated that food restriction had a significant effect on the mass of all the reproductive organs (MANOVA; all $P<0.005)$, that temperature significantly affected the mass of the testes only $(P<0.001)$ and that there was no significant interaction between the two factors.

During dissection it became apparent that the mice within each of the groups had responded differently to the experimental conditions and possessed different amounts of body fat. The mice in each experimental group were subdivided according to their fat score and the mass of the reproductive organs was compared to determine whether the ability of mice to resist fat loss had an effect on their reproductive organs (Fig. 2). Although the sample sizes for some fat scores were low, there is a clear trend in which the mice with the highest fat scores had the largest reproductive organs. The effect of fat on the mass of the reproductive organs was tested by giving each mouse a fat score of 0 (no

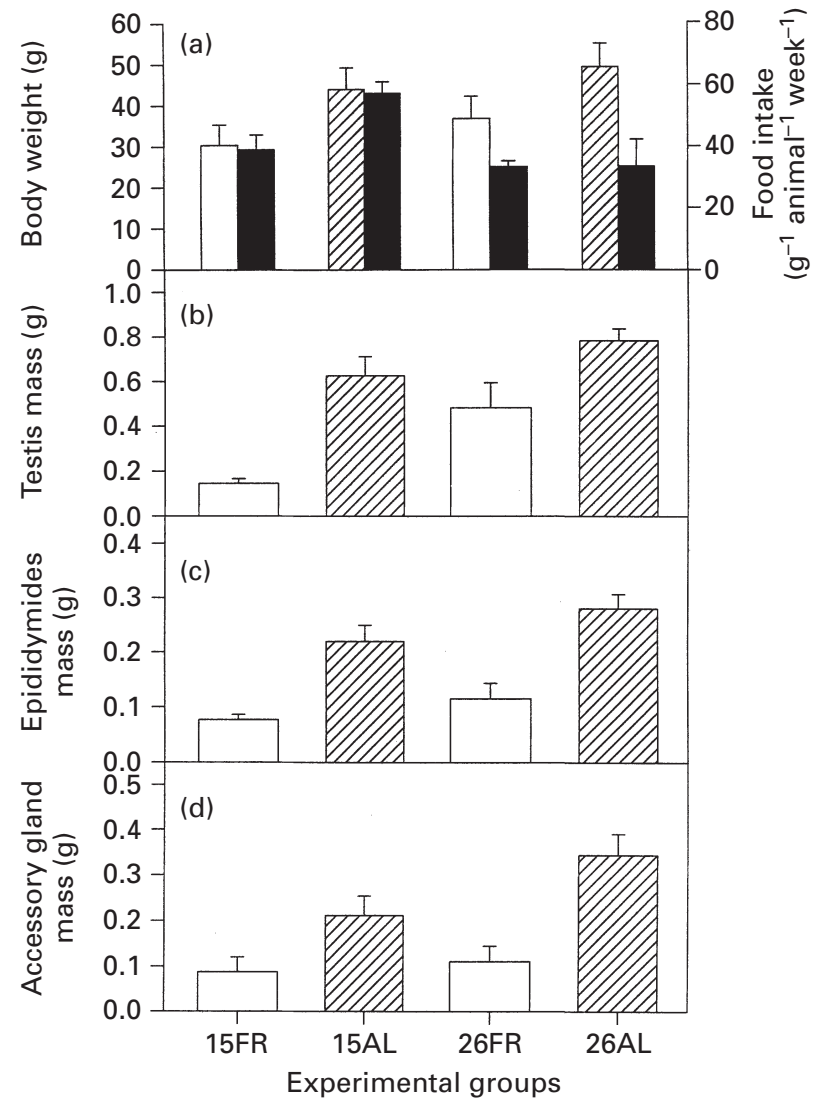

Fig. 1. Effect of reduced temperature and food availability on (a) body weight and (b,c,d) mass of the (b) testis, (c) epididymides and (d) accessory glands of male Rhabdomys pumilio at the time of dissection. In addition, mean food intake for each group is shown in (a; $\square$ ). $\square$ : Animals on food-restricted diet; $\square$ : animals on the ad libitum diet. $15 \mathrm{FR}: 15^{\circ} \mathrm{C}$, food-restricted diet; $15 \mathrm{AL}: 15^{\circ} \mathrm{C}$, ad libitum diet; 26FR: $26^{\circ} \mathrm{C}$, food-restricted diet; $26 \mathrm{AL}: 26^{\circ} \mathrm{C}$, ad libitum diet. Values are mean \pm SEM.

fat) or 1 (with fat) and this was included as a dummycovariable in a MANCOVA. The fat score had a significant effect as a covariate on body weight and the mass of all reproductive organs (all $P<0.05$ ). Once the effect of the fat 


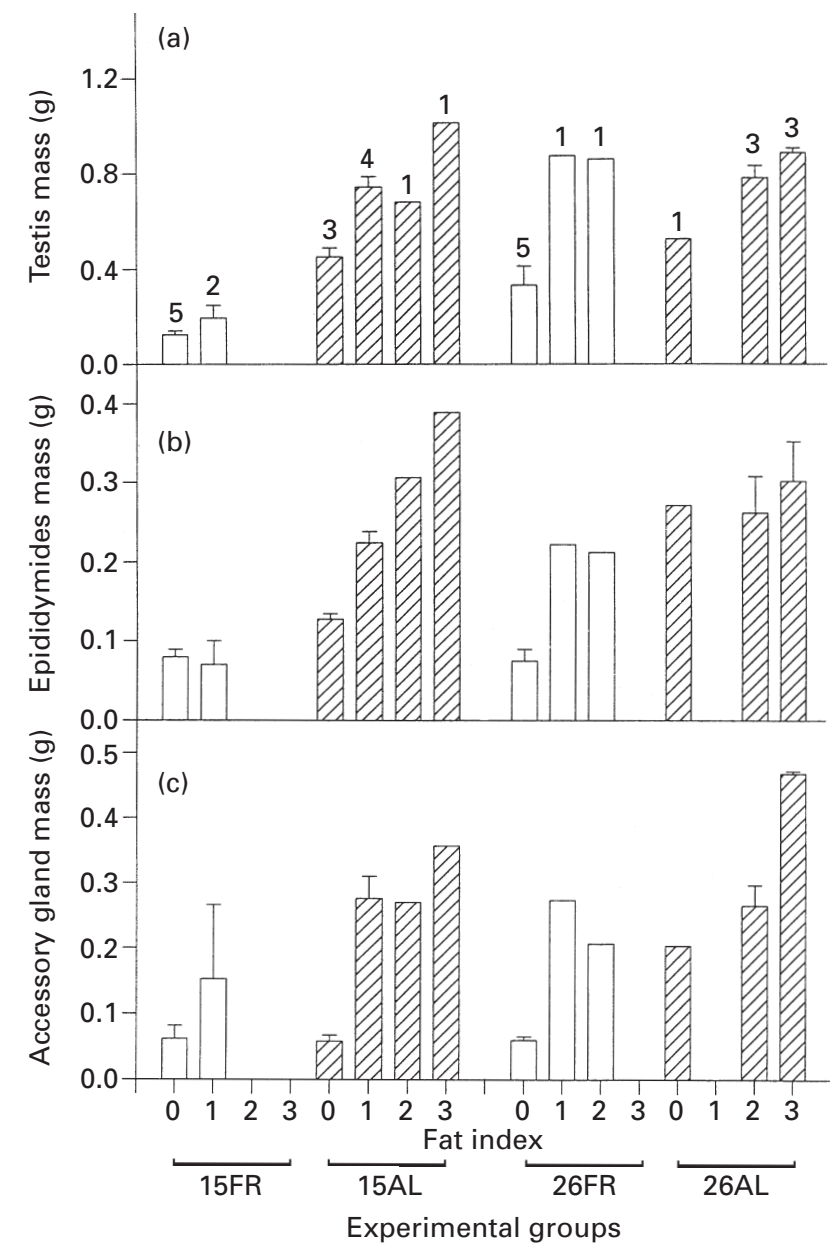

Fig. 2. The effect of body fat store on the mass of the reproductive organs of male Rhabdomys pumilio. Data from Fig. 1b-d have been subdivided according to the fat index given to the individual animals within the experimental groups. Numbers above the bars in (a) are sample sizes. $\square$ : Animals on food-restricted diet; $\square$ : animals on the ad libitum diet. $15 \mathrm{FR}: 15^{\circ} \mathrm{C}$, food-restricted diet; 15AL: $15^{\circ} \mathrm{C}$, ad libitum diet; $26 \mathrm{FR}: 26^{\circ} \mathrm{C}$, food-restricted diet; 26AL: $26^{\circ} \mathrm{C}$, ad libitum diet. Values are mean \pm SEM.

score had been removed, temperature still had a significant effect on the mass of the testes and also had an effect on the accessory glands (both $P<0.05$ ), food still had a significant effect on the mass of all reproductive organs, and there was a significant interaction between food and temperature on testis size $(P<0.001)$.

All the mice on the ad libitum diets at both temperatures were spermatogenically active, whereas six $(86 \%)$ of the $26 \mathrm{FR}$ mice and only one (14\%) of the 15FR mice were still producing spermatozoa (Table 3 and Fig. 3). Similar trends were observed in the activity of the reproductive accessory glands and in sperm storage in the cauda epididymides, both of which were greatest in the 26AL mice and lowest in the 15FR mice (Table 3). Analysis of these data after arcsine transformation (MANOVA) indicated that temperature $(P<0.01)$ and food $(P<0.001)$ separately had significant effects on spermatogenic activity and on sperm storage, but not on the activity of the accessory glands. Food and temperature interacted significantly to reduce spermatogenic activity $(P<0.001)$.

In conclusion, in male $R$. pumilio from the Eastern Cape Province, both reduced ambient temperature and a reduction in available food had inhibitory effects on development and activity of the reproductive organs, which was greatest when the two factors were combined and the effect of fat was removed.

\section{Experiment 2 (females)}

At the start of the experiment none of the females were pregnant but all had a perforate vagina. At dissection, all the mice in the 15FR group, five $(63 \%)$ of the $15 \mathrm{AL}$ mice, eight $(89 \%)$ of the $26 \mathrm{FR}$ mice and three $(37 \%)$ of the $26 \mathrm{AL}$ mice had a non-perforate vagina (Table 4 ).

During the experiment, there was a significant decrease in the body weight of the mice on the food-restricted diets (repeated measures $t$ test; $P<0.005$ ), with those in the 15FR group losing $23.3 \%$ of their original weight and those in the 26FR group losing $22.6 \%$ (Table 4). The mice in the $15 \mathrm{AL}$ group showed no significant change in body weight; however, the body weight of the mice in the $26 \mathrm{AL}$ group increased significantly $(P<0.001$; Table 4$)$. Comparison of the mean body weights of mice from the four groups at dissection (Fig. 4a) showed that while a reduction in food had a significant negative effect (MANOVA; $P<0.0001$ ), temperature had no effect and there was no significant interaction between the two factors (MANOVA). In the final week of the experiment, the mice in the $26 \mathrm{AL}$ group ate more than any other group in either experiment (see Figs 1 and 4), which probably explains the significant increase in body weight of these mice.

A reduction in food availability had a greater effect on the mass of the female reproductive organs (Fig. 4b,c) than did temperature and, for example, the mean mass of the uterus in mice of the 26FR group was very similar to that of mice in the 15FR group (Fig. 4b). Statistical analysis of these data confirmed that food restriction had a significant effect on the mean mass of the uterus and ovaries (MANOVA; $P<0.05)$, but that temperature did not (MANOVA), and there was no significant interaction between the two factors. As with the males, at dissection the females had different amounts of fat, and mice with the largest amount of fat had the largest reproductive organs. However, the inclusion of the fat index as a dummy covariable in a MANCOVA indicated that fat had a significant effect on body weight only $(P<0.001)$ and that removing the effects of fat did not change the results from the MANOVA.

External examination of the ovaries revealed the presence of a number of protruding structures that were confirmed as corpora lutea by histology. The number of corpora lutea visible on the outside of the ovaries was affected significantly by food availability but not by temperature; the food-restricted mice had fewer corpora 
Table 3. The effect of a reduction in ambient temperature and food availability on the occurrence of spermatogenesis, sperm storage and activity of the accessory glands of Rhabdomys pumilio

\begin{tabular}{lccc}
\hline Experimental group & Spermatogenically active $(\%)$ & Epididymal sperm store $(\%)$ & Accessory gland activity $(\%)$ \\
\hline $26 \mathrm{AL}$ & 100 & $95.1 \pm 1.6$ & $95.1 \pm 3.1$ \\
$26 \mathrm{FR}$ & 100 & $54.3 \pm 10.9$ & $78.6 \pm 10.8$ \\
$15 \mathrm{AL}$ & 14 & $78.6 \pm 10.5$ & $75.0 \pm 13.7$ \\
$15 \mathrm{FR}$ & & $17.8 \pm 8.9$ & $49.8 \pm 16.7$ \\
\hline
\end{tabular}

26AL: $26^{\circ} \mathrm{C}$, ad libitum diet; $26 \mathrm{FR}: 26^{\circ} \mathrm{C}$, food-restricted diet; $15 \mathrm{AL}: 15^{\circ} \mathrm{C}$, ad libitum diet; $15 \mathrm{FR}: 15^{\circ} \mathrm{C}$, food-restricted diet.
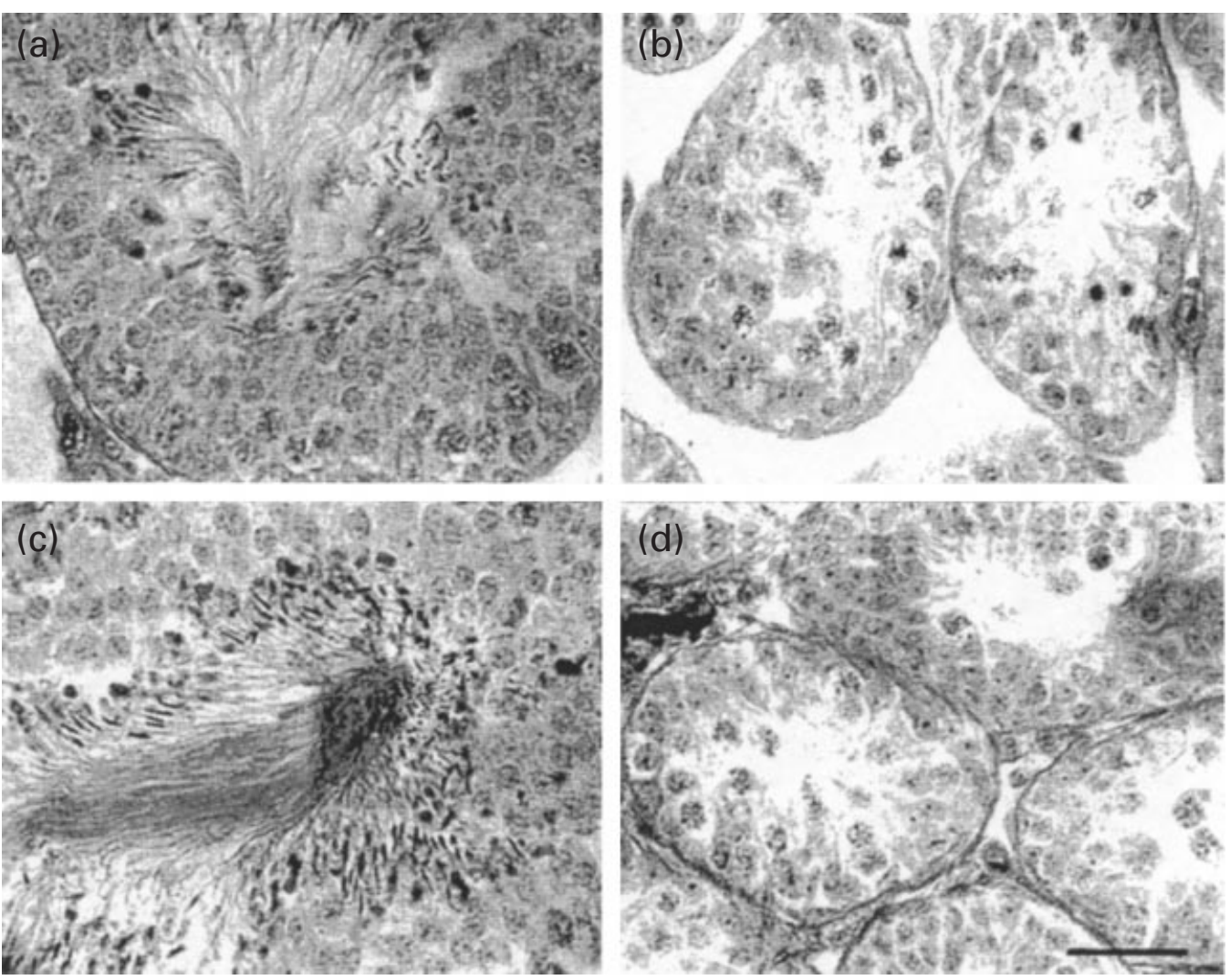

Fig. 3. Light micrographs of histological sections of Rhabdomys pumilio testis showing the typical appearance of the seminiferous tubules after 4 weeks exposure to (a) $26^{\circ} \mathrm{C}$, ad libitum, (b) $26^{\circ} \mathrm{C}$, foodrestricted, (c) $15^{\circ} \mathrm{C}$, ad libitum and (d) $15^{\circ} \mathrm{C}$, food-restricted, diets. Scale bar represents $25 \mu \mathrm{m}$.

lutea than did the ad libitum mice (Fig. 5; MANOVA, $P<0.05)$. A similar trend was seen in the numbers of secondary and Graafian follicles, which were significantly lower in the food-restricted mice than in the mice fed ad libitum (Fig. 6; MANOVA, $P<0.05$ for both). Temperature had no effect on the numbers of developing follicles and there was no significant interaction between the two factors. There was no significant difference in the mean size of the corpora lutea between the groups but the corpora lutea from the ovaries of the mice on the food-restricted diet were more vascularized than those from mice on the ad libitum diet (Figs 5 and 7). A comparison of the subjective score given to the extent of vascularization indicated that only food had a significant effect (MANOVA, $P<0.05$ ).

The various measures of the development of the uterus (total thickness of the uterine wall, thickness of the myometrium and thickness of the endometrium) all yielded similar results (Figs 8 and 9). Development of the uterus was reduced significantly in the food-restricted groups irrespective of temperature (MANOVA; $P<0.001$ for all). Temperature had no significant effect on development of the uterus and there was no significant interaction between the two factors. The abundance of uterine glands was highest in the 26AL group and similarly reduced in the other 
Table 4. The effect of a reduction in ambient temperature and food availability on body weight and vaginal perforation of Rhabdomys pumilio

\begin{tabular}{|c|c|c|c|c|c|c|c|}
\hline \multirow{2}{*}{$\begin{array}{l}\text { Experimental } \\
\text { group }\end{array}$} & \multicolumn{2}{|c|}{ Mean body weight \pm 1 SEM $(g)$} & \multirow{2}{*}{$\begin{array}{l}\% \text { Change in } \\
\text { body weight }\end{array}$} & \multicolumn{2}{|c|}{ Perforate vagina (\%) } & \multicolumn{2}{|c|}{ Non-perforate vagina (\%) } \\
\hline & Start & End & & Start & End & Start & End \\
\hline $26 \mathrm{AL}$ & $40.7 \pm 2.6$ & $52.8 \pm 1.8$ & +29.7 & 100 & 63 & 0 & 37 \\
\hline $26 \mathrm{FR}$ & $44.3 \pm 3.4$ & $34.3 \pm 3.4$ & -22.6 & 100 & 11 & 0 & 89 \\
\hline $15 \mathrm{AL}$ & $44.5 \pm 3.6$ & $47.2 \pm 3.3$ & +6.07 & 100 & 37 & 0 & 63 \\
\hline $15 \mathrm{FR}$ & $42.5 \pm 2.7$ & $32.6 \pm 2.1$ & -23.3 & 100 & 0 & 0 & 100 \\
\hline
\end{tabular}

26AL: $26^{\circ} \mathrm{C}$, ad libitum diet; $26 \mathrm{FR}: 26^{\circ} \mathrm{C}$, food-restricted diet; $15 \mathrm{AL}: 15^{\circ} \mathrm{C}$, ad libitum diet; $15 \mathrm{FR}: 15^{\circ} \mathrm{C}$, food-restricted diet.

Note that the sample size at the end of the experiment differed from that at the start.

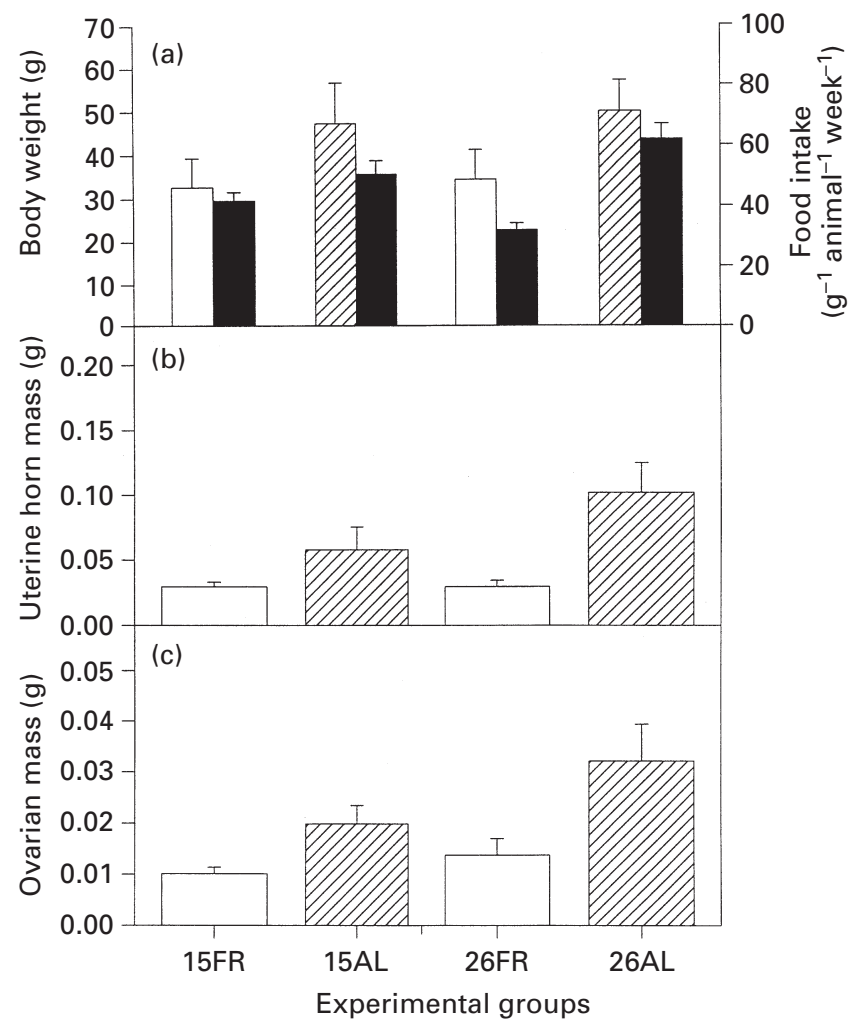

Fig. 4. Effect of reduced temperature and food availability on (a) body weight and mass of (b) uterine horns and (c) ovaries of female Rhabdomys pumilio at the time of dissection. Mean food intake for each group is shown in (a; $\mathbf{\square}) . \square$ : Animals on food-restricted diet; $叉$ : animals on the ad libitum diet. $15 \mathrm{FR}: 15^{\circ} \mathrm{C}$, food-restricted diet; 15AL: $15^{\circ} \mathrm{C}$, ad libitum diet; $26 \mathrm{FR}: 26^{\circ} \mathrm{C}$, food-restricted diet; 26AL: $26^{\circ} \mathrm{C}$, ad libitum diet. Values are mean \pm SEM.

groups (Fig. 8c). Statistical analysis of these data (MANOVA) showed that temperature had a significant effect on the abundance of uterine glands $(P<0.05)$ but that food availability did not, and there was no significant interaction between the two factors.

In conclusion, in female $R$. pumilio from the Eastern Cape Province, there is evidence that reproduction is

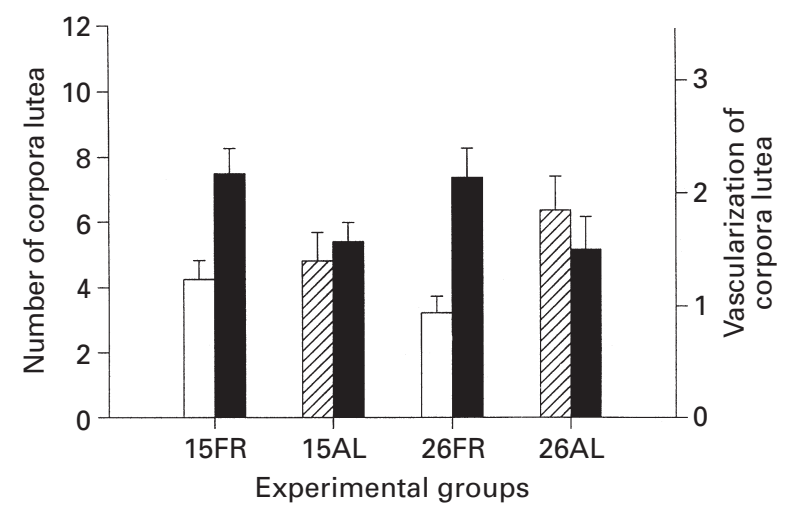

Fig. 5. Effect of reduced temperature and food availability on the number ( $\square$ : food-restricted diet; $\square$ : ad libitum diet) and vascularization ( $\mathbf{\square}$ ) of Rhabdomys pumilio corpora lutea. 15FR: $15^{\circ} \mathrm{C}$, food-restricted diet; $15 \mathrm{AL}: 15^{\circ} \mathrm{C}$, ad libitum diet; $26 \mathrm{FR}: 26^{\circ} \mathrm{C}$, food-restricted diet; $26 \mathrm{AL}: 26^{\circ} \mathrm{C}$, ad libitum diet. Values are mean \pm SEM.

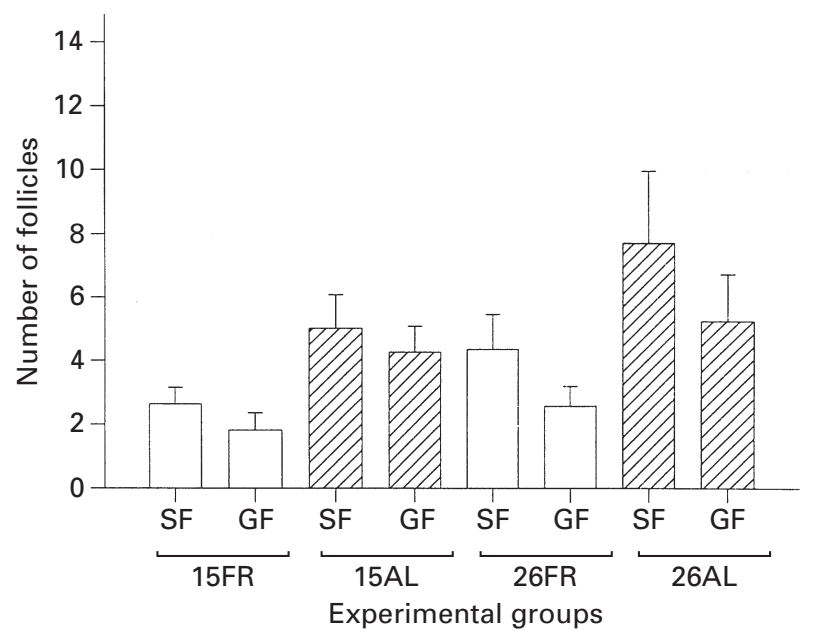

Fig. 6. The effect of reduced temperature and food availability on the number of secondary (SF) and Graafian (GF) follicles in the ovaries of female Rhabdomys pumilio. $\square$ : Food-restricted diet; $\square$ : ad libitum diet. $15 \mathrm{FR}: 15^{\circ} \mathrm{C}$, food-restricted diet; $15 \mathrm{AL}: 15^{\circ} \mathrm{C}$, ad libitum diet; 26FR: $26^{\circ} \mathrm{C}$, food-restricted diet; $26 \mathrm{AL}: 26^{\circ} \mathrm{C}$, ad libitum diet. Values are mean \pm SEM. 

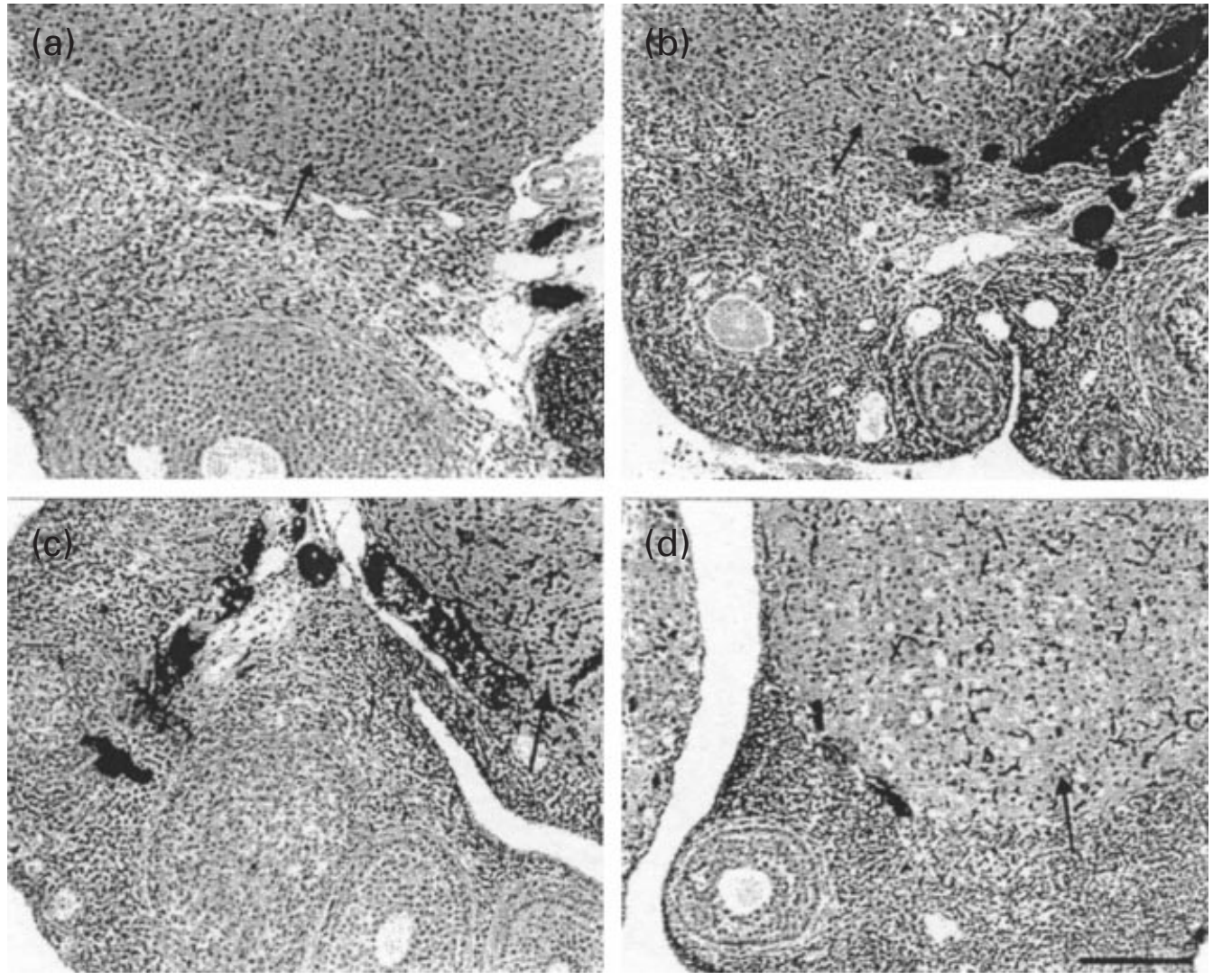

Fig. 7. Light micrographs of histological sections showing the extent of vascularization of the corpora lutea (arrows) of Rhabdomys pumilio after exposure to (a) $26^{\circ} \mathrm{C}$, ad libitum, (b) $26^{\circ} \mathrm{C}$, food-restricted, (c) $15^{\circ} \mathrm{C}$, ad libitum and $(\mathrm{d}) 15^{\circ} \mathrm{C}$, food-restricted, diets. Scale bar represents $100 \mu \mathrm{m}$.

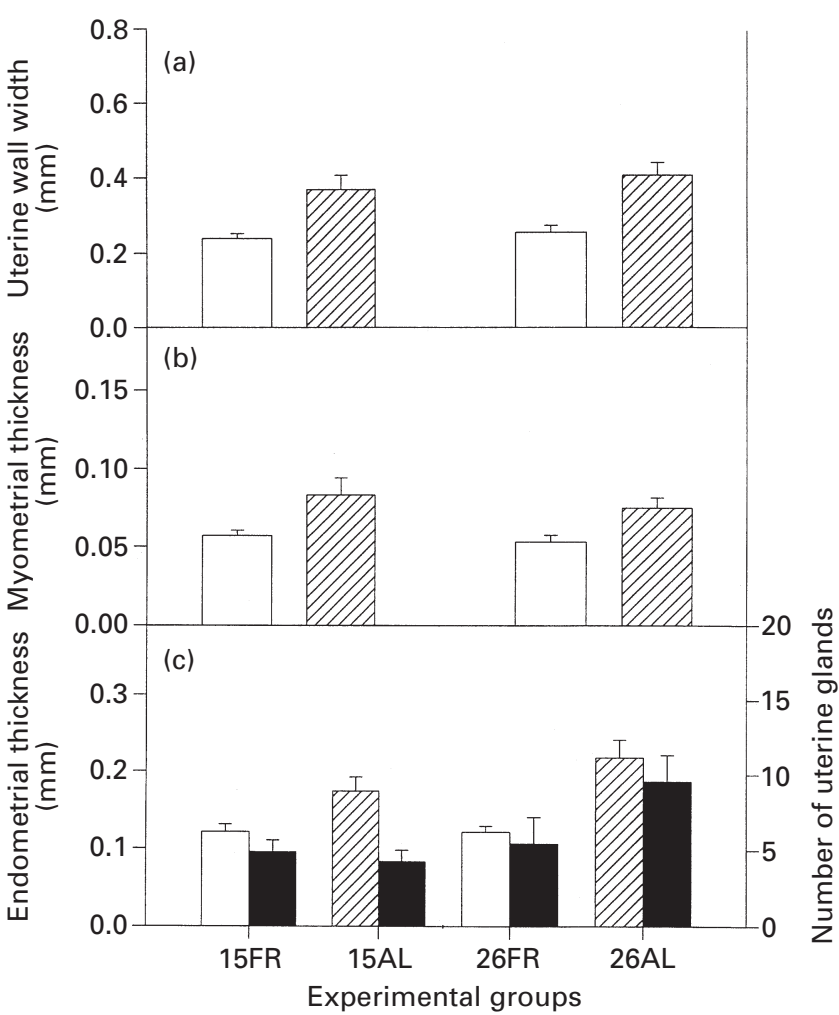

inhibited by a reduction in food quantity irrespective of ambient temperature. The masses of the ovaries and uterus, the numbers of developing follicles and corpora lutea, and the development of the uterine wall were all reduced by food deprivation at $26^{\circ} \mathrm{C}$ to levels similar to those that resulted from a reduction in ambient temperature to $15^{\circ} \mathrm{C}$ either with or without a reduction in the amount of food available.

\section{Discussion}

Of the many environmental factors that can influence the timing of mammalian reproduction, seasonal food availability is thought to be the most important cause of seasonal reproduction (Bronson, 1989; Bronson and Heideman, 1994). Indeed, a number of experiments have been conducted on rodents and other mammals to test their responses to varying food availability, either by providing

Fig. 8. The effect of reduced temperature and food availability on the thickness of the (a) uterine wall, (b) myometrium and (c) endometrium in Rhabdomys pumilio. The mean number of uterine glands is shown in (c; $\mathbf{\square}) . \square$ : Food-restricted diet; $\square$ : ad libitum diet. $15 \mathrm{FR}: 15^{\circ} \mathrm{C}$, food-restricted diet; $15 \mathrm{AL}: 15^{\circ} \mathrm{C}$, ad libitum diet; 26FR: $26^{\circ} \mathrm{C}$, food-restricted diet; $26 \mathrm{AL}: 26^{\circ} \mathrm{C}$, ad libitum diet Values are mean \pm SEM. 

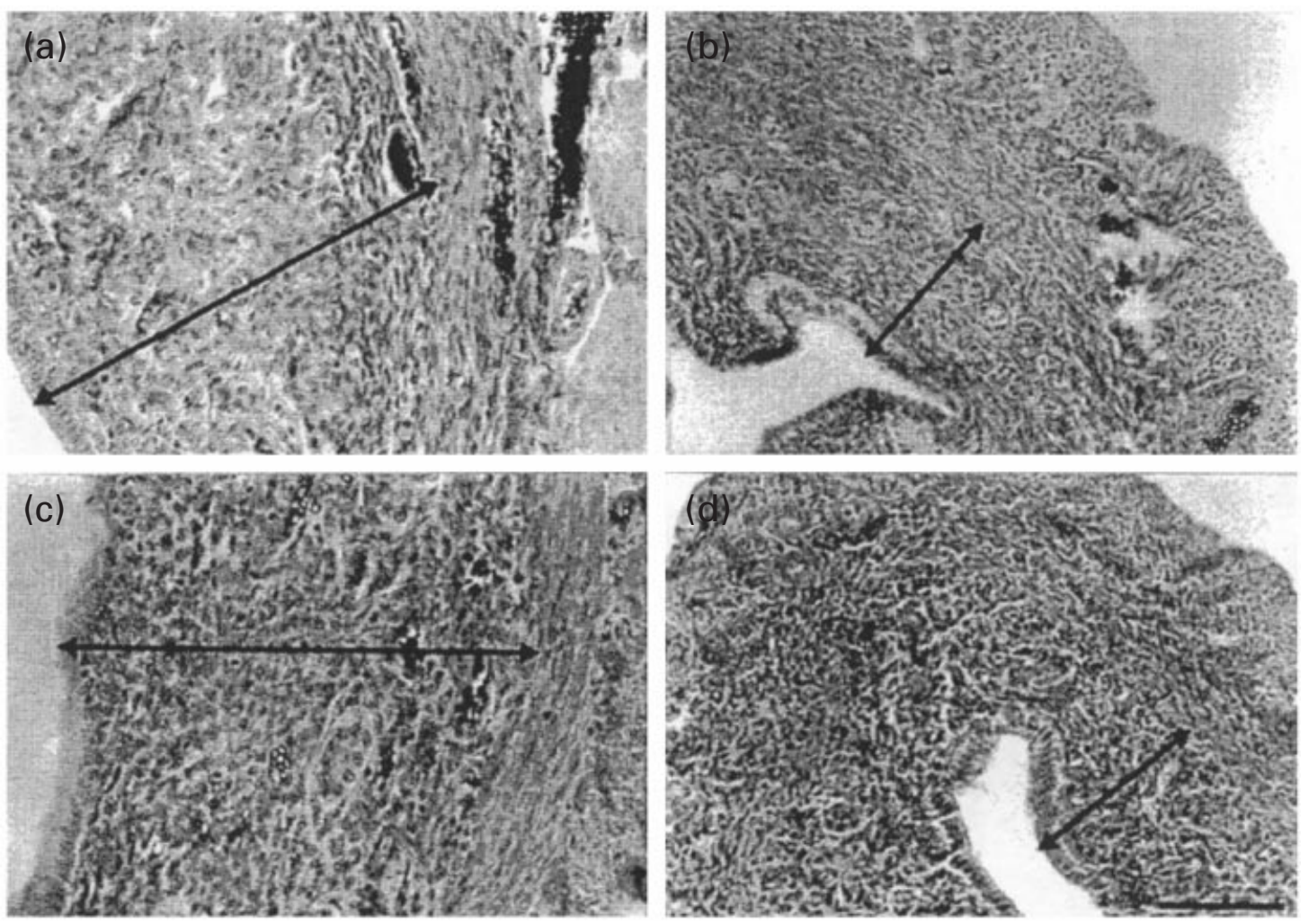

Fig. 9. Light micrographs of histological sections through the uterus of Rhabdomys pumilio exposed to (a) $26^{\circ} \mathrm{C}$, ad libitum, (b) $26^{\circ} \mathrm{C}$, food-restricted, (c) $15^{\circ} \mathrm{C}$, ad libitum and (d) $15^{\circ} \mathrm{C}$, food-restricted, diets. The line in each panel indicates the thickness of the endometrium. Scale bar represents $50 \mu \mathrm{m}$.

populations with long-term food supplementation (Alibhai, 1985; Cittadino et al., 1994; Duquette and Millar, 1995; Galindo-Leal and Krebs, 1998; Millar et al., 1998), shortterm food supplementation (Pinter and Negus, 1965), shortterm food deprivation (Bazhan et al., 1996) or long-term food restriction (Hamilton and Bronson, 1985). Although these experiments have used different approaches to study the effects of food availability, the fundamental results are similar. Animals that are provided with a food supplement of either green plant matter (Pinter and Negus, 1965; Alibhai, 1985) or oats and sunflower seeds (Galindo-Leal and Krebs, 1998) all show an increase in reproductive activity, while mice exposed to either short-term or longterm food deprivation all experience some form of depression of reproductive activity (Hamilton and Bronson, 1994; Bazhan et al., 1996). In studies involving both males and females of a species, the females respond to a greater extent than do the males (wild house mouse: Hamilton and Bronson, 1994; Pampean grassland mouse: Cittadino et al., 1994; rock mouse: Galindo-Leal and Krebs, 1995) and it has been suggested that females are generally more susceptible to reproductive inhibition than are males (Bronson, 1989; Bronson and Heideman, 1994). The results of the present study on Rhabdomys pumilio support these findings, as a $10 \%$ reduction in food availability resulted in a reduction in spermatogenic activity and follicular development, and a reduction in the masses of the reproductive organs of males and females. Furthermore, males and females responded differently in terms of both weight loss and reproductive inhibition. In males, weight loss was greatest and maximum inhibition was achieved when food restriction was combined with reduced ambient temperature. In females, ambient temperature did not affect weight loss of mice on the food-restricted diets and maximum reproductive inhibition was achieved by food restriction, irrespective of ambient temperature. The differential sensitivity of the two sexes to the environmental cues may have evolved as a result of their different contributions to reproduction after fertilization. After fertilization, males will make little or no further contribution to production and rearing of the young, whereas females carry all the energy costs and all the risks of pregnancy and lactation (Bronson and Perrigo, 1987; Bronson, 1989). It is also likely that the different development times for spermatozoa and oocytes could be important in dictating the different responses of males and females to environmental factors. For these reasons we propose that female $R$. pumilio have evolved a system whereby reproduction is inhibited rapidly by a reduction in energy intake, irrespective of ambient temperature. 
There have been few studies on the effects of ambient temperature only on reproductive activity and it has been suggested that the reaction of an animal to temperature changes or challenges will depend on both its genotype and its previous experience (Bronson, 1989). Low ambient temperature has little effect on the reproductive capability of male mammals; however, for females of small size, low temperatures can cause a depression of reproductive activity (Bronson, 1989). In the present study, reduced ambient temperature alone significantly reduced the number of uterine glands but had no other significant effect on female reproductive activity. In contrast, in male fourstriped field mice, temperature alone had a more pronounced effect on reproduction and reduction in ambient temperature resulted in a significant reduction in mass of the testes and accessory glands (after removal of the effect of fat), and in spermatogenesis and sperm storage. In both sexes, the inhibitory effect of reduced ambient temperature alone was less marked than that of a reduction in food availability.

The results of the present study indicate that the inhibitory effects of a reduction in ambient temperature and food on reproduction are influenced by the body fat reserves of an animal. Although it has been reported that fat reserves are important for successful reproduction in female mammals (Duquette and Millar, 1995), there has been little other evidence to support this (Bronson and Manning, 1991; Duquette and Millar, 1995) and more recently, the concept of a direct link between body fat store and reproduction has been questioned (Wade et al., 1996). The males and females used in the present study had variable abilities to resist fat loss and a few animals that had been deprived of food had retained a certain amount of subcutaneous fat. In male R. pumilio, there was a significant positive relationship between the fat index and the size of all reproductive organs, whereas in females, the same trend was present but the effect was not significant. In male $R$. pumilio, maximum inhibition of reproduction was achieved when a reduced ambient temperature was combined with food reduction. This combination would place the mice under the greatest energy challenge, which would result in rapid use of fat reserves. It is therefore not surprising that the fat score had a significant effect on reproductive activity. We suggest that in females, reproductive activity was inhibited before fat reserves were expended and, thus, there was no significant relationship between fat score and reproductive activity.

Although female reproductive activity was inhibited by a reduction in food availability, the ovaries of mice that had been on the food-restricted diet for 8 weeks contained corpora lutea that were more vascularized than those of mice on the ad libitum diet. Although this finding might indicate that these mice had recently ovulated, this possibility is believed to be unlikely. The mice on the foodrestricted diet had significantly fewer secondary and Graafian follicles in the ovaries and it appeared that follicular development had been inhibited. This observation is supported indirectly by the structure of the endometrium of the mice on the food-restricted diets, which appeared not to be under the stimulation of ovarian hormones. An alternative explanation is that the natural degeneration of the corpora lutea from the final oestrous cycle was inhibited in these mice. Finally, it is well-established that the effect of nutrition on reproductive physiology is mediated via changes in activity of the gonadotrophin-releasing hormone neurones (Wade et al., 1996) and, clearly, the functional and morphological changes reported in the present study reflect changes in the secretion and release of hormones by the hypothalamic-pituitary-gonad axis.

In conclusion, the four-striped field mouse reproduces seasonally in the wild with little or no reproductive activity in winter. Under laboratory conditions, reproductive activity is not inhibited by short daylength alone (Jackson and Bernard, 1999) but is inhibited by a reduction in ambient temperature and food availability (present study). The response of female $R$. pumilio was different from that of males, and an ability to resist fat loss provided a buffer against the effects of reduced ambient temperature and reduced food availability. These are characteristics of opportunistic reproduction, which, in its purest form, is independent of photoperiod influences, and dictates that males remain sexually ready throughout the year and that females either remain sexually active throughout the year or breed seasonally depending on the availability of energy and nutrient resources (Bronson and Heideman, 1994). The ability of some mice to resist fat loss will result in those mice continuing to reproduce, whereas reproduction is inhibited in other mice, thereby resulting in a degree of heterogeneity in the population. It is concluded that reproduction in $R$. pumilio, in the Eastern Cape Province, is opportunistic and is inhibited, not by short daylength, but whenever the combination of ambient temperature and food availability results in a sustained energy challenge. Although the effects of ambient temperature and food abundance have been examined in the present study, other factors such as food quality and time spent obtaining food will affect the energy balance and, therefore, would also be expected to affect reproduction.

The authors would like to thank all those who helped during the trapping of the mice, especially Mr and Mrs G. Gush for the use of their farm and for their assistance while trapping. The authors would also like to thank K. Wilkins for her assistance with the histology and the FRD (now NRF) and Rhodes University, who provided funding.

\section{References}

Alibhai SK (1985) Effects of diet on reproductive performance of the Bank vole (Clethrionomys glareolus). Journal of Zoology, London 205 445-452

Bazhan NM, Makarova EN and Yakovleva TV (1996) Deprivation of food during pregnancy and reproduction in the water vole (Arvicola terrestris). Journal of Mammalogy 77 1078-1084

Bernard RTF and Hall J (1995) Failure of the estrous cycle and spermatogenesis to respond to day length in a subtropical African 
rodent, the Pouched mouse (Saccostomus campestris). Biology of Reproduction 52 1291-1295

Bronson FH (1989) Mammalian Reproductive Biology pp 1-325. University of Chicago Press, Chicago

Bronson FH and Heideman PD (1994) Seasonal regulation of reproduction in mammals. In The Physiology of Reproduction pp 541-583 Eds E Knobil and JD Neill. Raven Press, New York

Bronson FH and Manning JM (1991) The energetic regulation of ovulation: a realistic role for body fat Biology of Reproduction 44 945-950

Bronson FH and Perrigo G (1987) Seasonal regulation of reproduction in muroid rodents American Zoology 27 929-940

Brooks PM (1974) The Ecology of the Four-striped Field Mouse, Rhabdomys pumilio (Sparrman, 1784) with Particular Reference to a Population on the Van Riebeeck Nature Reserve Pretoria PhD Thesis, University of Pretoria

Cittadino EA, De Carli P, Busch M and Kravetz FO (1994) Effects of food supplementation on rodents in winter Journal of Mammalogy $\mathbf{7 5}$ 446-453

Clarke JR (1985) The reproductive biology of the bank vole (Clethrionomys glareolus) and the wood mouse (Apodemus sylvaticus). Symposium of the Zoological Society of London 55 33-59

David JHM and Jarvis JUM (1985) Population fluctuations, reproduction and survival in the striped fieldmouse Rhabdomys pumilio on the Cape Flats, South Africa Journal of Zoology, London 207 251-276

De Graaf G (1981) The Rodents of Southern Africa pp 202-207. Butterworth \& Co, South Africa

Duquette LS and Millar JS (1995) Reproductive response of a tropical mouse, Peromyscus mexicanus, to changes in food availability Journal of Mammalogy 76 596-602

Galindo-Leal C and Krebs CJ (1998) Effects of food abundance on individuals and populations of the rock mouse (Peromyscus difficilis). Journal of Mammalogy 79 1131-1142

Hamilton GD and Bronson FH (1985) Food restriction and reproductive development in wild house mice Biology of Reproduction 32 773-778

Hanney P (1965) The muridae of Malawi (Africa: Nyasaland) Journal of Zoology, London 146 577-633

Harvey PH and Zammuto RM (1985) Patterns of mortality and age of first reproduction in natural populations of mammals Nature 321 648-649

Henschel JR, David JHM and Jarvis JUM (1982) Age determination and age structure of a striped fieldmouse, Rhabdomys pumilio, population from the Cape Flats South African Journal of Zoology 17 136-142

Irby DC, Kerr JB, Risbridger GP and de Kretser DM (1984) Seasonally and experimentally induced changes in testicular function of the Australian bush rat (Rattus fuscipes). Journal of Reproduction and Fertility $\mathbf{7 0}$ $657-666$

Jackson C and Bernard RTF (1999) Short day length alone does not inhibit spermatogenesis in the seasonally breeding four-striped field mouse (Rhabdomys pumilio). Biology of Reproduction 60 1320-1323

Millar DW, Blache D, Boukhliq R, Curlewis JD and Martin GB (1998) Central metabolic messengers and the effects of nutrition on gonadotrophin secretion in sheep Journal of Reproduction and Fertility $112347-356$

Nelson RJ, Kita M, Blom JMC and Rhyne-Grey J (1992) Photoperiod influences the critical caloric intake necessary to maintain reproduction among male deer mice (Peromyscus maniculatus). Biology of Reproduction 46 226-232

O'Brien GM, Curlewis JD and Martin L (1993) Effect of photoperiod on the annual cycle of testis growth in a tropical mammal, the little red flying fox, Pteropus scapulatus. Journal of Reproduction and Fertility $\mathbf{9 8}$ $121-127$

Partridge L and Harvey PH (1985) Costs of reproduction Nature 321 648-649

Perrin MR (1980) Ecological strategies of two co-existing rodents South African Journal of Science 76 487-491

Pinter AJ and Negus NC (1965) Effects of nutrition and photoperiod on reproductive physiology of Microtus montanus. American Journal of Physiology 208 633-638

Promislow DEL and Harvey PH (1990) Living fast and dying young: a comparative analysis of life-history variation among mammals Journal of Zoology, London 220 417-437

Read AF and Harvey PH (1989) Life history differences among eutherian radiations Journal of Zoology, London 219 329-353

Smithers RHN (1971) The mammals of Botswana Museum Memoirs of National Museums and Monuments of Rhodesia 4 1-340

Trillmich F (2000) Effects of low temperature and photoperiod on reproduction in the female wild guinea pig (Cavia aperea). Journal of Mammalogy 81 586-594

Wade NG, Schneider JE and Hi-Yun Li (1996) Control of fertility by metabolic cues American Journal of Physiology 33 E1-E19

Zar JH (1996) Biostatistical Analysis pp 1-662. Prentice Hall Inc, Englewood Cliffs, New Jersey

Resubmitted 8 February 2001.

First decision 3 April 2001.

Accepted 22 May 2001. 